\title{
Un siglo del Manifiesto Liminar: acción política y rebeldía en Defensa de la Universidad colombiana ${ }^{1}$
}

\author{
Manifiesto Liminar celebrates a century: political action and rebellion in \\ defense of the Colombian University
}

Um século do Manifesto Liminar: ação política e rebeldia na defesa da universidade colombiana

\author{
Álvaro Acevedo Tarazona ${ }^{2}$ \\ Andrés David Correa Lugos ${ }^{3}$ \\ Universidad Industrial de Santander (Colombia)
}

Recepción: 25/05/2017

Evaluación: 04/09/2017

Aceptación: 05/01/2018

Artículo de investigación - Reflexión

DOI: https://doi.org/10.19053/01227238.7874

\section{RESUMEN}

El objetivo de este artículo de reflexión es analizar el impacto que tiene el Manifiesto Liminar en el accionar político y social de los movimientos sociales universitarios en Colombia. Los estudiantes universitarios utilizan un relato en el cual proponen la rebeldía como el espíritu aglutinante y lo que justifica sus acciones colectivas, esta visión compartida por los jóvenes de Córdoba indica una conexión entre ambas. Este artículo es derivado de un proyecto de investigación que usa una metodología cualitativa con enfoque interpretativo, el cual triangula fuentes primarias como la prensa con entrevistas semiestructuradas y balances historiográficos. Por último, sostiene que la "identidad" generada en medio de la rebeldía y las acciones colectivas en las décadas de 1960 y 1970 sufre una transformación en la década de 1980 hasta llegar al punto máximo de su languidez, cuando el mismo discurso de la revolución es adaptado por el sistema en medio de las reformas neoliberales.

Palabras clave: Revista de Historia de la Educación Latinoamericana; autonomía educativa; movimiento estudiantil; Reforma de la educación; Universidad.

1 Este artículo de reflexión es producto del proyecto de investigación "El ocaso de la utopía antisistémica: la universidad, el conflicto y la apuesta por la paz en Colombia 1968-1998”. Código: 8262, financiado por Colciencias y ejecutado por la Universidad Industrial de Santander.

2 Posdoctorado en Ciencias de la Educación. Profesor Titular Universidad Industrial de Santander. Director del Grupo de Investigación Políticas, Sociabilidades y Representaciones Histórico-Educativas. Correo electrónico: tarazona20@gmail.com.

3 Historiador y Archivista. Miembro del Grupo de Investigación Políticas, Sociabilidades y Representaciones Histórico-Educativas. Correo electrónico: andrescorrealugos@outlook.com. 


\begin{abstract}
The objective of this reflection article is to analyze the impact that the Manifesto Liminar has on the political and social actions of the university movements in Colombia. University students' speech propose rebellion as the agglutinating spirit that justifies their collective actions; this vision, shared by the youth of Cordoba, strongly suggest a connection between both movements.

This article is derived from a research project that uses a qualitative methodology with an interpretive approach. Primary sources such as the press with semi-structured interviews and historiographic balances are triangulated. Finally, it is stated that the "identity" generated in the midst of rebellion and collective actions in the 1960s and 1970s underwent a transformation in the 1980s to reach the peak of its languor, when the same speech of revolution is adapted by the system during the neoliberal reforms.

Keywords: Journal History of Latin American Education; academic autonomy; student movement; Education reform, University.
\end{abstract}

\begin{abstract}
RESUMO
O objetivo deste artigo de reflexão é analisar o impacto que teve o Manifesto Liminar em articular a dimensão política e social dos movimentos sociais universitários na Colômbia. Os estudantes universitários utilizam um relato no qual propõem a rebeldia como o espírito aglutinador e o que justifica suas ações coletivas; visão que, compartilhada pelos jovens de Córdoba, indica uma conexão entre ambas. Este artigo é resultado de um projeto de pesquisa que usa uma metodologia qualitativa com enfoque interpretativo, o qual triangula fontes primárias, como a imprensa com entrevistas semiestruturadas e balanços historiográficos. Por último, sustenta que a "identidade" gerada em meio da rebeldia e as ações coletivas nas décadas de 1960 e 1970 sofre uma transformação na década de 1980 até chegar ao ponto máximo de seu esmorecimento, quando o mesmo discurso da revolução foi adaptado pelo sistema em meio às reformas liberais.

Palavras-chave: Revista de História da Educação Latino-americana; autonomia educativa; movimento estudantil; Reforma da educação; Universidade.
\end{abstract}

\section{INTRODUCCIÓN}

Las universidades han sido nodos de rebeldía, autonomía y libertad. La unión de estas tres hace posible que en los campus universitarios se pueda crear, pensar y discutir desde las esferas académicas los distintos rasgos sociales y políticos de la sociedad. La tradición hace que las universidades latinoamericanas sean históricamente una extensión de grupos o élites acomodadas, con la modernidad, esta concepción de la educación superior es debatida. El Manifiesto Liminar es el primer intento latinoamericano por demostrar la inconformidad por parte de las juventudes universitarias. Si bien, a cien años de dicho acontecimiento aún existe un debate frente a la utilidad política y educativa del mismo, lo que es innegable es el aporte que ha dado al imaginario rebelde de la universidad en toda Latinoamérica.

Ahora bien, para hallar el aporte del Manifiesto Liminar a Latinoamérica, y siendo más específicos a Colombia, es necesario dilucidar que la fortaleza del documento reposa en dos conceptos fundamentales que al día de hoy siguen 
movilizando jóvenes: la acción política y la rebeldía. Este binomio acompañado de la vivencia universitaria consigue que los jóvenes logren crear una visión de lo que es la universidad y el mundo fuera de ella. Este ejercicio de conocimiento y distinción deriva en una territorialidad de la universidad, es por esta razón, que la defensa de la autonomía es tan importante en las universidades ${ }^{4}$. No es un discurso que posibilita hacer lo que se quiera, es más bien el ejercicio de un deber del cual depende la universidad tal y como se conoce.

Este artículo de reflexión tiene por objetivo analizar la universidad desde la construcción de topologías que forjan territorios identitarios. En otras palabras, explica cómo desde la interrelación social y el uso de los discursos por parte del estudiantado, es posible crear vínculos que definan el porvenir y la proyección de los actores sociales y de la universidad como colectivización de un target poblacional. Esta colectivización es posible por la creación de objetivos comunes frente a problemas compartidos.

En razón de lo anterior, el artículo primero desarrolla un marco teórico en el que explica la construcción del concepto de territorio y cómo este puede ser apropiado por distintos grupos poblacionales y formar inclusive territorios dentro de otros territorios, todos ellos comunicados por los discursos y las cargas de representaciones sociales. La construcción del territorio es importante porque permite explicar la solidaridad o camaradería presente dentro de las universidades y su afianzamiento en situaciones clave como son los paros, las marchas y los mítines.

Una vez explicada la categoría, el artículo se adentra en la descripción fenomenológica del territorio como una causalidad cuyo objetivo principal es mostrar a los universitarios como un "nosotros" comprometido con causas políticas y sociales. Este fenómeno latinoamericano puede encontrarse en el Manifiesto Liminar y si se exploran con cuidado las movilizaciones sociales estudiantiles desde las décadas de 1960 y 1970 se puede rastrear una continuidad del mismo y una transición en los años ochenta.

Si existe un "nosotros" lo más probable es que exista un "otro", este ejercicio de distinción es el más importante y es el que faculta las movilizaciones sociales, pues siempre van a necesitar de un "otro" antagónico hacia quién dirigir la rebeldía y la indignación. Como estos movimientos son antisistémicos, la creación del "otro" es dirigida hacia el oficialismo y todo lo que represente el establishment.

Si bien parece algo monocromático e incluso dualista, es esa la intención del análisis. La rebeldía y la revolución del siglo XX tienen una herencia histórica que necesita de dos bandos o protagonistas, es una revolución moderna con un discurso moderno y una proyección del porvenir al mejor estilo del materialismo histórico. Lo que no ha sido capaz de percibir la rebeldía es el cambio del discurso y la poca competencia que existe para cambiarlo. El Estado, o más bien

4 Hugo Biagini, "La cultura de la resistencia juvenil y el proceso emancipador", Revista de Historia de la Educación Latinoamericana No. 11, (2008): 59-76. José Molina Bravo. "Educación pública, autonomía universitaria y cambio político: Notas para el análisis del movimiento universitario en Chile, 2011”. Revista Historia de la Educación Latinoamericana. Vol. 15 No, 21, (2013): 263 - 282. 
"lo otro", toma la acción política y la revolución para construir desde el Estado ligeros cambios que no afectan el statu quo, pero sí ofrecen una mejor cara de la institucionalidad. La radicalización y el dogmatismo no logran su objetivo y poco a poco el territorio y el nosotros forjado por los estudiantes queda en desuso, lo que se traduce en la crisis identitaria de los movimientos sociales desde la década de los noventa hasta hoy, hasta el punto que actualmente es difícil conceptualizar un movimiento estudiantil y a lo sumo se logran grandes movilizaciones. El equilibrio de la movilización y la vida universitaria afecta otras dimensiones como la construcción y la conceptualización autonómica de la universidad haciendo que lo de Córdoba sea un recuerdo para conmemorar pero que tenga poco impacto en una sociedad del rendimiento, en la cual la universidad se encuentra burocratizada y politizada.

\section{Marco teórico}

Autonomía y revolución son dos conceptos comunes en las dinámicas universitarias y la construcción social del campus. El objetivo de este artículo es desarrollar una topología de la universidad latinoamericana desde la segunda mitad del siglo XX. Es una topología porque analiza el espacio como un constructo social en derivación y fricción. El filósofo surcoreano Byung-Chul Han expone las topologías como manifestaciones macrofísicas establecidas en relaciones bipolares entre el yo con el otro, entre dentro y afuera. Las manifestaciones topológicas son explosivas, materiales y expresivas ${ }^{5}$. En otras palabras, analizar la topología de la universidad es entablar una relación entre las inflexiones de las posturas presentes en el territorio delimitado como "la universidad". Es importante entonces, hacer una caracterización entre lo que se define entre el yo como nosotros -que es la comunidad universitaria- y el ellos -como el establishment-. Este acercamiento produce fricciones que en las sociabilidades de la segunda mitad del siglo XX lleva a un reformismo en las políticas educativas y una reconceptualización de la autonomía universitaria a partir de las experiencias movilizadoras.

La territorialización de la universidad como un espacio propicio para generar un nosotros como primer paso en la construcción de la autonomía universitaria, lleva a analizar las fricciones en coyunturas puntuales como las reformas catalogadas de imperialistas por los estudiantes universitarios, los intentos políticos del Estado para ahogar las movilizaciones y las lógicas neoliberales y nihilistas que acaparan la atención de los jóvenes. Todas estas coyunturas conviven dentro de la universidad como territorio:

Es un espacio en que los actores sociales se delimitan y articulan con otros existentes. El territorio puede ser relativo tanto a un espacio vivido, como a un sistema percibido dentro del cual un sujeto se siente "una cosa". El territorio es sinónimo de

5 Byung-Chul Han, Topología de la violencia (Madrid: Herder, 2016), 8. 
apropiación, de subjetivación fichada sobre sí misma. Es un conjunto de representaciones las cuales van a desembocar, pragmáticamente, en una serie de comportamientos, inversiones, en tiempos y espacios sociales, culturales y cognitivos ${ }^{6}$.

El territorio de la universidad no es la delimitación de los predios, es el intrincado sistema social, cultural y político en el que la idea de universidad reformula las relaciones sociales y se une con otras territorialidades para ejercer un compromiso de autodeterminación, autonomía y pertenencia con la alma máter.

Este artículo dilucida el tránsito de la universidad como territorio -donde confluyen ideas y prácticas antisistémicas, antioligárquicas y antiimperialistas heredadas del Manifiesto Liminar ${ }^{7}$ - a un espacio donde se discute la transformación social con las estrategias dispuestas por el mismo establishment. En menos de un siglo las formas de movilización y los contenidos de las acciones colectivas cambian drásticamente, lo que implica una desterritorialización de la universidad como núcleo antisistémico a una universidad como referente para legitimar al Estado, en la cual la misma autonomía, por defecto, cambia sus horizontes y objetivos.

\section{Yo (como) nosotros}

La universidad latinoamericana moderna tiene su origen hace un siglo con la consigna del Manifiesto Liminar de Córdoba. Es importante puntualizar que es "moderna", no por el marco espacio-temporal que ocupa sino porque hace eco a la necesidad y levantamiento de las masas cuando se trata de injusticia y desigualdad. No en vano, el investigador Jacques Le Bon afirma a finales del siglo XIX que en ese momento se está ad portas de un periodo de transición y anarquía previo a la era de las masas. Las masas representan la voz del pueblo, pero también son máquinas reconstitutivas de las formas del poder ${ }^{8}$, son fundadoras de sindicatos y precursoras de movimientos sociales que exigen transformaciones puntuales en la cotidianidad.

Frente a esta impronta de cambio, la universidad recoge las múltiples dinámicas movilizadoras de movimientos obreros y campesinos. La proyección no se hace esperar, muy pronto los actores sociales que están en la universidad adquieren compromisos y apoyan a los sectores que representan la masa y de los cuales tienen relaciones muy estrechas. Entre los factores que comparten se encuentran las formas de lucha que justifican la rebeldía como síntoma de la sociedad en búsqueda de un cambio y, la crítica y recuperación de los espacios que por siglos han pertenecido a élites y que la masa ahora exige:

6 Félix Guattari y Suely Rolnik, Micropolítica: cartrografías del deseo (Madrid: Traficantes de Sueños, 2006), 21.

7 Luis Armando Rébora, La reforma universitaria 1918-1988 (Buenos Aires: Legasa, 1989), 28.

8 Jacques Le Bon, Psicología de las masas (Madrid: Morata, 1995), 20. 
La rebeldía estalla ahora en Córdoba y es violenta, porque aquí los tiranos se habían ensoberbecido y porque era necesario borrar para siempre el recuerdo de los contra-revolucionarios de mayo. Las universidades han sido hasta aquí el refugio secular de los mediocres, la renta de los ignorantes, la hospitalización segura de los inválidos y -lo que es peor aún-el lugar en donde todas las formas de tiranizar y de insensibilizar hallaron la cátedra que las dictara9.

Desde este momento se perfila una forma de lucha rebelde que en ocasiones justifica la violencia como único método válido para hacerse visible. El uso de la violencia no solo enfatiza en las tipologías de violencia explícita y negativa, como herir al otro, sino que también se usan formas de violencia implícita o positiva, las cuales son inherentes a los discursos y atacan tanto al otro que representa a la tiranía y a sectores de la masa que no se comprometen con la revolución.

Las demandas de la masa no son solo de espacios de transformación, la masa también reclama educación, desarrollos de las disciplinas científicas y concibe que tanto la cultura como la ciencia deben servir a la revolución y no estar simplemente al servicio de la burocracia:

Por eso es que la Ciencia, frente a estas casas mudas y cerradas, pasa silenciosa o entra mutilada y grotesca al servicio burocrático. Cuando en un rapto fugaz abre sus puertas a los altos espíritus es para arrepentirse luego y hacerles imposible la vida en su recinto. Por eso es que, dentro de semejante régimen, las fuerzas naturales llevan a mediocrizar la enseñanza, y el ensanchamiento vital de los organismos universitarios no es el fruto del desarrollo orgánico, sino el aliento de la periodicidad revolucionaria ${ }^{10}$.

La ciencia y la cultura son dos metas muy importantes para la revolución, y es por medio de la universidad que es posible acceder a ellas. Gran parte de los esfuerzos de las universidades y su tendencia revolucionaria del siglo XX llevan a demostrar que se puede crear una ciencia y una cultura al servicio del pueblo y la revolución ${ }^{11}$. En las universidades latinoamericanas este impulso de renovación llega con los estudios marxistas y el materialismo histórico, la lucha de clases más que ser una explicación dialéctica marxista, se convierte en un referente ideológico y militante para los jóvenes y una nueva generación de maestros:

El marxismo proporciona conocimientos esenciales de la naturaleza, de la ciencia moderna inasequibles desde cualquier otra perspectiva, y proporciona la base para apreciar sus éxitos o analizar críticamente sus debilidades. Pero esto por sí mismo no es suficiente. El marxismo no es simplemente una teoría para contemplar el mundo.

$9 \quad$ Universidad Nacional de Córdoba, Manifiesto Liminar de la Reforma Universitaria de 1918. La Juventud Argentina de Córdoba a los Hombres Libres de Sudamérica, (Córdoba: Universidad Nacional de Córdoba, 1918) https://www.unc.edu.ar/sobre-la-unc/manifiesto-liminar (30 de diciembre, 2017)

10 Ibíd.

11 En perspectiva, tanto la Unión Soviética como Estados Unidos han burocratizado la ciencia y la han llevado al epítome con la carrera espacial entre los años de 1957 y 1975. Se estima que los soviéticos tenían un presupuesto anual de 6900 millones de rublos (más o menos 4500 millones de dólares), mientras que los estadounidenses unos 5000 millones de dólares. Véase: James Oberg, Final frontier (New York: Grolier, 1992). 
Es un arma revolucionaria que tiene como objetivo el derrocamiento del sistema capitalista. La crítica marxista de la ciencia como existe actualmente es simultáneamente un llamado para su transformación, un llamado para liberarla de las limitaciones ideológicas y materiales de una sociedad basada en provecho para unos pocos ${ }^{12}$.

Es a partir de las relaciones de territorialidades como la científica, la obrera y la campesina que el territorio de la universidad construye un porvenir de movilización, revolución y cambio social. Esta representación genera un sentimiento de aceptación por parte de los actores sociales que se involucran en la medida en que la universidad empieza a abrirse a más sectores de la población -en especial de la clase media-, y deja de ser un privilegio exclusivo de las élites. Esta nueva dinámica crea una brecha entre el oficialismo del Estado y los pasillos rebeldes de las universidades.

En Colombia esta coyuntura se dinamiza en la década de 1960 e inicios de la década de 1970. Es aquí cuando los preceptos autonómicos y de cogobierno, que son concebidos medio siglo atrás en el Manifiesto Liminar, empatan la construcción de un nosotros como juventudes comprometidas con el cambio y consideran que para cambiar la sociedad, lo primero que deben cambiar es su territorio, es decir, las relaciones de poder dentro de la universidad:

La juventud ya no pide. Exige que se le reconozca el derecho a exteriorizar ese pensamiento propio de los cuerpos universitarios por medio de sus representantes. Está cansada de soportar a los tiranos. Si ha sido capaz de realizar una revolución en las conciencias, no puede desconocérsele la capacidad de intervenir en el gobierno de su propia casa ${ }^{13}$.

El ejercicio de autonomía debe formar primero una identidad. El reconocimiento del yo como un nosotros es vital en la consolidación de un proyecto político que pueda ser exteriorizado. Ejemplos concretos conducen a repensar las formas de revolución de una búsqueda simple de las libertades a un ritus. Por ejemplo, los estudiantes comprometidos en los movimientos estudiantiles en la Universidad Industrial de Santander a finales de la década de los sesenta emulan experiencias revolucionarias castristas y maoístas:

Después del estallido de la Revolución cubana, la gente se emociona mucho y se imaginan con un fusil llegando a la Plaza de Bolívar siendo aclamados por la multitud (...) La vestimenta de los estudiantes de la UIS es pantalón "caqui", botas y camisa de un solo color, la gente se uniforma; a excepción de cuatro o cinco estudiantes que tienen carro, de resto, el más "montado" llega en bicicleta, ese movimiento hace que la gente empiece a leer cosas marxistas y libros para entender El capital y el materialismo histórico ${ }^{14}$.

12 Phill Gasper, "Marxismo y ciencia", Revista Teórica del Socialist Workers Party, No. 79 (1998).

13 Universidad Nacional de Córdoba. Manifiesto Liminar, op. cit.

14 Entrevista Bucaramanga, 27 de julio de 2017. 
Los jóvenes universitarios adoptan formas de expresión e identidad que los acercan a un ideal de revolución que no veían lejos. Es común el uso de indumentarias que contemplan el adiestramiento militar. Estas prácticas afianzan la ideología de los estudiantes y construyen una solidaridad al verse representados como un nosotros frente a otro extraño. La distinción no solo queda consignada en la forma de vestir, las modalidades de expresar ideas frente a la comunidad universitaria incitan a la construcción de espacialidades de la revolución orquestadas por los mismos estudiantes:

También existe proliferación de periódicos. En las paredes del edificio de Matemáticas en la UIS a las siete de la mañana, todo el mundo pone su periódico para expresarse, nadie toma el sitio del otro, se tratan temas políticos. Esa es una influencia de la Revolución china, y nosotros le llamábamos el dazibao porque ese es el boletín que cuelgan en las calles de Pekín, todo se hacía con mimeógrafo, con punzón o esténcil, la mayoría aprendimos de ortografía, redacción y diagramación ${ }^{15}$.

El uso del dazibao en las universidades colombianas genera una nueva reconceptualización en la construcción de los territorios. En la década de los sesenta los estudiantes de la UIS compiten entre sí para hacer los mejores dazibaos y encontrar también la mejor ubicación, que es frente a la cafetería principal. Posteriormente, los estudiantes no compiten entre sí por encontrar las mejores ubicaciones, sino por la permanencia de los mismos al ser removidos por orden directa de los rectores.

Es en estas prácticas como se forma la territorialidad de una universidad antisistémica. Es antisistémica por el uso de formas de lucha y la apología al uso de la fuerza para la consolidación de un objetivo: revertir el orden del sistema. Desde la segunda mitad del siglo XX estas prácticas son apoyadas por la comunidad:

Un domingo hicimos una ternera a la llanera con carne donada por la galería de la plaza de mercado, de todo había allá, y aprendimos a cocinar en olla grande. En la marcha a Bogotá de 1964 todo el mundo fue a apoyar, yo fui hasta Piedecuesta. En Málaga promovimos el movimiento estudiantil con dazibao en todas las esquinas, también con los profesores y estudiantes hicimos una marcha ${ }^{16}$.

La radicalización de las ideas y las acciones colectivas al igual que el uso excesivo de la fuerza y la represión del Estado llevan a un distanciamiento de la comunidad de las luchas estudiantiles ${ }^{17}$. El temor convierte la lógica comunista en una forma peyorativa e incluso punitiva de definir a alguien. La transformación del apoyo de la comunidad a un rechazo o mutismo cómplice de la repre-

\footnotetext{
15 Ibid.

16 Ibíd.

17 Álvaro Acevedo, 1968. Historia de un acontecimiento: utopía y revolución en la universidad colombiana (Bucaramanga: UIS, 2017), 201.
} 
sión tiene su origen en prácticas políticas como el Estatuto de Seguridad de 1978. Dicho estatuto, más que brindar seguridad a la población, hace que las personas se sientan vulnerables y presas fáciles de las acusaciones. El temor se toma las calles, los procesos extrajudiciales son llevados a cabo por el mismo Ejército o la Policía, los interrogatorios y las capturas expresas son prácticas comunes que modifican la territorialización de la universidad de un espacio de confrontación y debate a un territorio de miedo y hostigamiento.

Las crisis y las presiones por parte del Estatuto de Seguridad hacen que los estudiantes se unan más y reafirmen su identidad. Muy distinta es la suerte para los procesos autonómicos en las universidades. Los fallidos intentos del cogobierno universitario y las primeras incursiones en la implementación de lógicas neoliberales desde $1976^{18}$, golpean de manera drástica la composición identitaria del movimiento estudiantil hasta atomizarlo en querellas de referencias políticas, ideológicas y personales que disminuyen el impacto de la universidad en la sociedad.

En la década de 1980 los procesos de movilización estudiantil son reprimidos con mayor fuerza y violencia. Bajo la excusa de la lucha contra las guerrillas, el terrorismo y el floreciente negocio del narcotráfico, cualquier forma de protesta es considerada como una desestabilización al sistema. El enemigo interno es potencializado y los modus operandi puestos a prueba en el Estatuto de Seguridad mutan a un terror estatal soterrado que deja un saldo de miles de muertos en todo el país:

Me llevaron a un calabozo oscuro en el cuartel Ricaurte de la policía. Cuando la gente fue a preguntar por mí, no aparecía en el registro; había un policía que se ensanó conmigo, un motorizado que me provocaba para que yo hiciera algo (...) Fue un gran momento de miedo, así no fuera muy consciente de la magnitud de lo que podía pasar $^{19}$.

En este momento la movilización estudiantil es consciente del peligro al que se enfrenta. Muchos estudiantes que hacen parte de las movilizaciones se retiran al ver cómo empiezan a caer uno a uno sus compañeros, o son alejados por maniobras poco convencionales de represión y temor llevadas a cabo por la misma fuerza pública. El simple hecho de ser un estudiante de universidad pública es motivo suficiente para temer por la vida. En rechazo a esta práctica discriminatoria por parte de la fuerza pública, el Estado e incluso los medios de comunicación deforman la identidad del estudiante universitario hasta tildarlo de guerrillero; de igual manera, el territorio de la universidad es tildado de invernadero de "revoltosos". En respuesta, los estudiantes hacen marchas en las que ironizan la lógica de represión que se presenta:

18 Medófilo Medina, “El neoliberalismo en Colombia y las alternativas de las luchas sociales 1975-1998”, en Lucha popular, democracia y neoliberalismo, eds. Margarita López Maya (Caracas: Nueva Sociedad, 1998), 152-178.

19 Entrevista, Bogotá, 26 de julio de 2017. 
En la Universidad Nacional, tener un carné era un referente para ser perseguido, eso nos unía mucho. Me acuerdo que cuando me detuvieron en una marcha tenía el carné en la mano, después hicimos una marcha en la que todos los estudiantes de la Nacional llevábamos el carné en lo alto. Creo que el tema del universitario está ligado a la universidad pública, hay un estigma sobre el estudiante ${ }^{20}$.

El estigma hacia el estudiantado es alimentado por los medios de comunicación que se refieren a los estudiantes en las protestas como guerrilleros, y empatan rebeldía y revolución como una excusa para legitimar la criminalidad por parte de los grupos insurgentes y el uso excesivo de la fuerza por parte de los militares y policías. El epítome de esta dinámica se produce el 16 de mayo de 1984 cuando los estudiantes de la Universidad Nacional deciden protestar contra la estigmatización que tiene el movimiento estudiantil. Los estudiantes hacen un acto simbólico en la Plaza Che, después deciden salir hacia la calle 26 para visibilizar la situación a la comunidad, y es allí cuando la Policía recibe las órdenes de tomarse la universidad y detener a los estudiantes. Se estima que los estudiantes muertos fueron diecisiete y cientos de heridos. Esta incursión de la fuerza pública deriva en el cierre por cerca de un año de la Universidad Nacional y el desmonte de la cafetería principal, las residencias universitarias y otras garantías propias del bienestar universitario.

A partir de la toma de la Universidad Nacional en el año de 1984 se puede considerar que existe un punto de inflexión en la configuración de la territorialización de la universidad. Existen relatos que muestran la furia desmedida con que las fuerzas policiales ingresan al campus:

Vi caer estudiantes heridos cuando corría hacia las residencias femeninas; encontrándome cerca de Agronomía alcancé a ver cuando la policía apaleaba a alguien y luego de estarla golpeando durante casi un minuto le dieron un tiro [...] Llegando a las residencias femeninas vemos como las fuerzas militares, la motorizada y en fin todo el pelotón de las fuerzas militares se metió a la universidad por la entrada de la 26. Al ver que la motorizada venía hacia nosotros nos tocó meternos en las residencias femeninas toda la gente que estaba viendo la cuestión. Como a los diez minutos de estar observando llegó una compañera y nos dijo que unos armados querían entrar a las residencias femeninas amenazando al celador que si no se abría la puerta le metían un tiro. Ya llegando al tercer piso...se nos aparecieron unos tipos armados por la espalda, diciendo más o menos esto "alto, el que corra le disparamos"21.

A partir de este momento el yo universitario, como nosotros de los estudiantes universitarios, cambia de manera abrupta. Las tensiones generadas por los asesinatos a líderes sindicales, de izquierda y activistas hacen que los estudiantes abran el debate de la movilización y dejen de pensar la universidad antiim-

20 Ibíd.

21 Proyecto Memoria y Palabra, 16 de mayo de 1984: 28 años de silencio. Recorrido de la Memoria (Bogotá: Universidad Nacional de Colombia, 2012) http://memoriaypalabra.blogspot.com.co/2012/05/16-de-mayo-del-84-28-anos-de-silencio.html (31 de diciembre, 2017). 
perialista y antioligárquica y se preocupen porque se garanticen unos mínimos vitales como es el derecho a la vida: "Posteriormente la represión vino con la mano negra, con el asesinato de muchos compañeros; por eso nuestra actividad gira en torno de la defensa de la vida y los derechos humanos. En un momento crítico éramos dos o tres los amenazados, yo tuve suerte, pero estuve preso varias veces"22.

La apertura del movimiento estudiantil hacia problemáticas cívicas, o más bien humanitarias, coincide con el surgimiento de lo que en Europa se denominan nuevos movimientos sociales. Antonio Negri define estas nuevas movilizaciones como reinvenciones sociales con base en poderes constituyentes. Lo que buscan es integrar en una lucha común los distintos discursos y acciones colectivas, a la vez que proponen alternativas de cambio recurriendo a lo político. Estos nuevos movimientos no buscan la revolución ni tratan de acabar con los esquemas hegemónicos. Esto hace que no tengan un esquema lógico de las acciones colectivas, tampoco un concepto unitario de antagonismo ni de construcción de una base mínima común para retomar el movimiento de masas ${ }^{23}$.

La única diferencia de los nuevos movimientos sociales europeos con los de Colombia, siguiendo a Negri, es que los primeros son efecto de un giro político y concertado en tanto que los segundos surgen como una urgencia ante la incapacidad del movimiento estudiantil de resistir la represión y la violencia del Estado y de grupos armados al margen de la ley. Por lo demás todo es igual, sobre todo en la incapacidad para retomar el movimiento de masas. Es precisamente esta incapacidad la que concluye la era de la universidad moderna y abre el escenario a una universidad de autonomía individualizada, donde la capitalización del sí-mismo es el objetivo primario tanto de la alma máter como de los estudiantes que la integran.

\section{El Estado como (lo) otro}

Los conceptos de rebeldía y revolución presentan cargas conceptuales apasionantes y convincentes. Ante las presiones del Estado y de grupos ilegales, los estudiantes universitarios desatienden la lógica de la revolución, entendida como el advenimiento de algo nuevo y mejor. Casi al instante que esto pasa, el Estado emula el concepto de revolución para sí como una estrategia para avalar reformas de corte neoliberal que buscan terminar con el proteccionismo que hay en el país.

El presidente César Gaviria elegido para gobernar el país entre los años de 1990 y 1994, presenta a los colombianos su programa de gobierno denominado "La revolución pacífica". El prólogo enfatiza que el carácter democrático del país es el único fundamento de cambio y revolución. La revolución de la que habla Gaviria es civilista y está enmarcada en el nacimiento de una asamblea constituyente. El modelo que presenta limita el intervencionismo social del Estado,

22 Entrevista, Bogotá, 26 de julio de 2017, óp. cit.

23 Antonio Negri, Fin del invierno (Buenos Aires: La Isla de la Luna, 2008), 23. 
aunque promete mejorar la cobertura en educación secundaria de un $46 \%$ a un $70 \%$ en los cuatro años de gobierno ${ }^{24}$. Algo que sobresale en dicho prólogo es el reconocimiento del malestar social que tienen los colombianos, lo cual hace que no exista credibilidad en las instituciones. La denominada revolución que emprende el mismo Estado cambia el modo de funcionar de los ministerios y también plantea una descentralización de los organismos del Estado con el fin de que estos tengan una autonomía local.

En el sector universitario las revoluciones de Gaviria llegan con la Ley 30 de 1992. El objetivo de esta ley es que las universidades continúen con la dinámica de apertura económica que el gobierno viene estableciendo como política transversal. La reforma concibe como uno de sus pilares a la investigación. Lógicamente esta debe buscar inversión privada, además plantea que solo las universidades con posgrados y doctorados son las llamadas a investigar. De igual manera, la reforma crea el Consejo Nacional de Educación Superior (Cesu), cuya misión es recomendar políticas educativas al gobierno nacional y definir condiciones de alta calidad a los programas e instituciones por intermedio del Consejo Nacional de Acreditación. El Cesu tiene la función de establecer lineamientos de acreditación de las instituciones y unificar los títulos que otorgan las mismas.

Un aspecto muy importante que fundamenta la Ley 30 es la capacidad de las universidades de elegir sus directivos, ordenar el presupuesto y fijar costos de matrículas. Esta carta blanca que tienen las universidades es entendida por el Estado como autonomía universitaria. De igual manera, la ley enfatiza que todas las universidades deben invertir un mínimo de $2 \%$ del presupuesto para bienestar universitario con el propósito de contribuir a la formación integral del estudiantado ${ }^{25}$.

Siguiendo los lineamientos presentados por Gaviria en materia de educación superior, las universidades públicas tendrán presupuestos del Estado, pero la prioridad educativa es para la enseñanza primaria y secundaria. Con la nueva ley el gobierno inicia todo un proceso para que las universidades sean autosostenibles; así, amplía el margen de ganancias por el cobro de derechos de matrícula y permite que las universidades celebren contratos con empresas privadas ${ }^{26}$.

Se puede considerar que las reformas a la educación superior a partir de la década de 1990 proponen una desterritorialización de la universidad. El afianzamiento de la apertura económica influye en la resignificación de conceptos como conocimiento, educación y autonomía. La principal razón que explica este proceso remite al proyecto gubernamental que busca liberarse de responsabilidades de índole social para adaptarse a nuevos estándares macroeconómicos. Las concesiones que hace el Estado en materia de bienestar institucional muestran que hay un conocimiento histórico de los pliegos de peticiones estudiantiles. Al reglamentar y garantizar una parte de los rubros universitarios en servicios de bienestar estudiantil, el Estado de alguna manera intenta contener futuras movilizaciones y protestas estudiantiles.

24 César Gaviría, La revolución pacífica (Bogotá: Presidencia de la República, 1991).

25 El Tiempo, "Esto es lo que busca la reforma" El Tiempo, Bogotá, 29 de septiembre de 1993.

26 Ibíd. 


\section{CONCLUSIÓN}

La autonomía universitaria más que un derecho y deber institucional es un principio que define la esencia de la universidad y dota a los estudiantes con actitudes y capacidades cívicas y democráticas. Es también un ejercicio de libertad que permite optar por la acción política o por la rebeldía. Las acciones colectivas son un factor fundamental para consolidar el compromiso social de los universitarios y, sobre todo, la defensa de la autonomía como principio que hace que los actores sociales se reconozcan como parte de la universidad. El hecho de decir "soy UPTC, soy UNAM, soy UIS" implica un empoderamiento de los individuos, una identificación por la defensa de la autonomía universitaria y una elección por abanderar compromisos de cambio social.

Este "nosotros" involucra una serie de acontecimientos que marca la historia de las universidades y de la sociedad. La universidad latinoamericana moderna está implicada en la mayoría de coyunturas sociales del siglo XX y es posible rastrear en ella opiniones, posturas o acciones frente al acontecer. Esto convierte a la universidad en un territorio protagónico en la historia contemporánea, en un lente que involucra múltiples perspectivas y debe ser considerada como una fuente historiográfica para comprender las dinámicas sociales.

La autonomía universitaria se forja con el esfuerzo, la acción política y la rebeldía de estudiantes, profesores, trabajadores y la comunidad. Ella ha formado la ilusión del cambio y el ideal de la calidad educativa. La historia de la universidad colombiana y latinoamericana ha mostrado una tendencia represiva o de contención a las ideas autonómicas o de cualquier forma de pensamiento que sea distinto a la conservación del statu quo. No obstante, la represión no aminora la movilización, por el contario, fortalece y aviva la solidaridad. Esta última, vitaliza la lucha $y$ la consecución de fines ${ }^{27}$.

Ahora bien, el uso de las formas represivas como intento para desgastar el movimiento estudiantil y los procesos autonómicos no logra su objetivo, pero sí deja un saldo de estudiantes violentados, desaparecidos y muertos. En la década de 1980 la violencia exacerbada que sufre Colombia convierte a los líderes estudiantiles, universitarios y profesores en objetivos. Esta situación crítica lleva a que la comunidad universitaria replantee sus intereses y piense que por encima de las luchas autonómicas está el derecho a la vida.

La represión, el miedo y, sobre todo, el afianzamiento de las lógicas neoliberales hacen que los estudiantes abandonen parcialmente la intensidad con que se defiende la autonomía y la concepción de la revolución. Una vez la abandonan, el Estado la adopta en el discurso político y promueve reformas neoliberales en las que paradójicamente la universidad termina siendo reformada y territorializada como un espacio de rendimiento, capitalización y estandarización.

El resultado a corto plazo es una pérdida de la huella de las luchas históricas universitarias. Los estudiantes no se sienten comprometidos con la universidad. Esto evidencia una crisis de la autonomía universitaria, pues los individuos son abocados a una libertad esclavizadora en la que el compromiso no es con la socie-

27 Alberto Melucci, “La acción colectiva como constructo social”, Estudios Sociológicos IX, No. 26 (1991): 357-358. 
dad sino con el sí mismo. No hay una interrelación de libertades y mucho menos de rebeldías. La autonomía está coaccionada por el mismo sistema y es custodiada por una intrincada burocracia que desdibuja el alcance social proyectado en el Manifiesto Liminar.

\section{FUENTES}

Proyecto Memoria y Palabra. 2012. Archivo Digital.

Entrevista, Bucaramanga, 26 de julio de 2017.

Entrevista, Bogotá, 27 de julio de 2017.

El Tiempo. 29 de septiembre de 1993. Archivo El Tiempo, Bogotá.

\section{REFERENCIAS}

Acevedo, Álvaro. 1968. Historia de un acontecimiento: utopía y revolución en la universidad colombiana. Bucaramanga: UIS, 2017.

Biagini, Hugo. "La cultura de la resistencia juvenil y el proceso emancipador". Revista de Historia de la Educación Latinoamericana, No. 11 (2008): 59-76.

Gasper, Phill. "Marxismo y ciencia”. Revista Teórica del Socialist Workers Party, No. 79 (1998).

Gaviría, César. La revolución pacífica. Bogotá: Presidencia de la República, 1991.

Guattari, Félix y Rolnik, Suely. Micropolitica: cartrografías del deseo. Madrid: Traficantes de Sueños, 2006.

Han, Byung-Chul. Topología de la violencia. Madrid : Herder, 2016.

Le Bon, Jacques. Psicología de las masas. Madrid: Morata, 1995.

Medina, Medófilo. "El neoliberalismo en Colombia y las alternativas de las luchas sociales 19751998". En Lucha popular, democracia y neoliberalismo editado por Margarita López Maya. Caracas: Nueva Sociedad, 1998, 152-178.

Melucci, Alberto. "La acción colectiva como constructo social”. Estudios Sociológicos IX, No. 26 (1991).

Molina Bravo, José. "Educación pública, autonomía universitaria y cambio político: Notas para el análisis del movimiento universitario en Chile, 2011". Revista Historia de la Educación Latinoamericana. Vol. 15 No, 21, (2013): 263 - 282.

Proyecto Memoria y Palabra, 16 de mayo de 1984: 28 años de silencio. Recorrido de la Memoria Bogotá: Universidad Nacional de Colombia, 2012. http://memoriaypalabra.blogspot.com. co/2012/05/16-de-mayo-del-84-28-anos-de-silencio.html (31 de diciembre, 2017).

Negri, Antonio. Fin del invierno. Buenos Aires: La Isla de la Luna, 2008.

Oberg, James. Final frontier. New York: Grolier, 1992.

Rébora, Luis Armando. La reforma universitaria 1918-1988. Buenos Aires: Legasa, 1989.

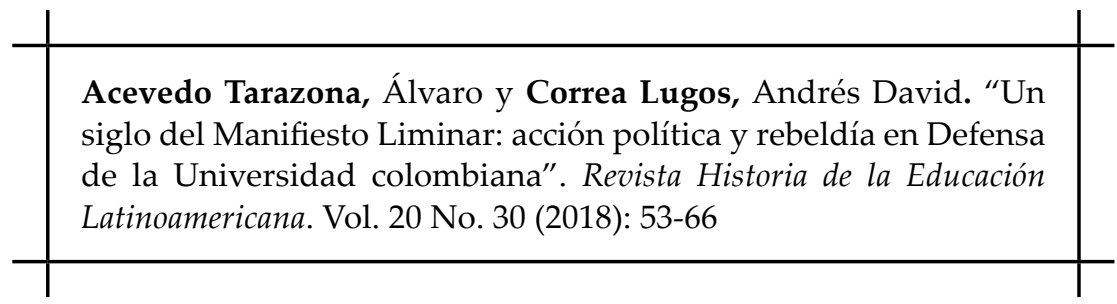

